\title{
A qualitative study of the seismo-ionospheric precursors prior to the 6 April 2009 earthquake in L'Aquila, Italy
}

\author{
G. S. Tsolis and T. D. Xenos \\ Aristotle University of Thessaloniki, Department of Electrical and Computer Engineering, 54006 Thessaloniki, Greece
}

Received: 14 July 2009 - Revised: 17 December 2009 - Accepted: 18 December 2009 - Published: 22 January 2010

\begin{abstract}
In this paper we use the Cross Correlation analysis method in conjunction with the Empirical Mode Decomposition to analyze foF2 signals collected from Rome, Athens and San Vito ionospheric stations, in order to verify the existence of seismo-ionospheric precursors prior to $M=6.3 \mathrm{~L}$ 'Aquila earthquake in Italy. The adaptive nature of EMD allows for removing the geophysical noise from the foF2 signals, and then to calculate the correlation coefficient between them. According to the cross correlation coefficient theory, we expect the stations which located inside the earthquake preparation area, as evaluated using Dobrovolsky equation, to capture the ionospheric disturbances generated by the seismic event. On the other hand the stations outside of this area are expected to remain unaffected. The results of our study are in accordance with the theoretical model, evidencing ionospheric modification prior to L'Aquila earthquake in a certain area around the epicenter. However, it was found that the selection of stations at the limits of the theoretically estimated earthquake preparation area is not the best choice when the cross correlation method is applied, since the modification of the ionosphere over these stations may not be enough for the ionospheric precursors to appear. Our experimental results also show that when a seismic event constitutes the main shock after a series of pre-seismic activity, precursors may appear as early as 22 days prior to the event.
\end{abstract}

\section{Introduction}

It is well known that earthquake activity contributes to ionospheric variability. Extensive studies in this field (Pulinets, 1997, 2004; Liperovsky et al., 2000; Ouzounov and Freund, 2001; Kouris et al., 2001; Molchanov et al., 2004;

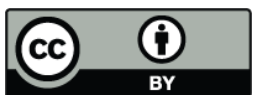

Correspondence to: G. S. Tsolis (strantis@gmail.gr)
Namgaladze et al., 2009), all point to the conclusion that the Earth's lithosphere interacts with the atmosphere prior to a strong seismic event, resulting in the generation of an anomalous electric field that affects the electron content of the ionosphere. However, the seismo-ionospheric interaction is considered a local event, meaning that only a certain area over the ground is affected by the earthquake, and its size is a function of the magnitude of the event. On the contrary solar activity, which is the primary contributor to ionospheric variability, affects the ionosphere as a whole, producing more global effects compared to the localized phenomena of seismo-ionospheric coupling. A real challenge here is how to distinguish between the seismic-generated foF2 fluctuations and the fluctuations attributed to solar activity. The problem becomes even more complicated when other smaller magnitude disturbances of undefined origin appear in the foF2 signal, which are known as geophysical or ionospheric noise (Davies, 1990; Kouris et al., 2001).

In this paper we continue a previous study of earthquakeoriented ionospheric disturbances, using the Cross Correlation method supplemented by the Empirical Mode Decomposition method, (Tsolis and Xenos, 2009). The model is tested here using the 6 April 2009, L'Aquila $M=6.3$ earthquake in Italy as the case study, which was a devastating event that left 297 people dead, 1000 more injured and about 66000 homeless.

\section{Cross correlation-EMD method}

The method used in this study is a combination of the Cross Correlation Analysis method proposed by Pulinets (Pulinets et al., 2004), and the Empirical Mode Decomposition proposed by Huang (Huang et al., 1998, 2005). The Cross Correlation method is just a correlation coefficient calculation of the foF 2 measurements from a station that it is located within the earthquake preparation area, compared with a similar foF2 signal from an ionospheric station located outside

Published by Copernicus Publications on behalf of the European Geosciences Union. 
the preparation area. The idea is that when the two stations are located relatively close together, solar activity-oriented disturbances will affect each station's foF2 measurements in the same way, and therefore the cross correlation coefficient is expected to be high in the absence of a seismic event. On the other hand, when a seismic event occurs in the vicinity of one of the two stations, the cross correlation coefficient drops, since the measurements from the station inside the earthquake preparation area are the only ones affected. However, the selection of the two stations requires careful consideration, as the distance between them must ensure that they are both equally subject to the same solar activity ionospheric disturbances, maintaining at the same time consistency with the in and out requirements of the earthquake preparation area for the seismo-ionospheric precursors to appear. More detailed information about the cross correlation analysis can be found in Pulinets (2004) and Tsolis and Xenos (2009).

The second part of the technique requires denoising the foF2 signals collected from the two stations using Empirical Mode Decomposition (EMD), an adaptive method for processing non-linear and non-stationary signals. EMD basically decomposes a real signal into its functional components, which are known as Intrinsic Mode Functions (IMF). This process derives information about the decomposition of the signal itself, without the requirement for a predefined basis, as do similar methods (i.e., wavelets). This means that the decomposition is driven itself and there are no a-priori decisions that may affect the final result.

A typical decomposition of a real signal using EMD results in a filter bank wavelet-like breakdown of the signal having a higher to lower frequencies hierarchy, (Flandrin et al., 2004a, b). Since the decomposition is executed in the time domain without losing time resolution as the order of scale increases, the initial signal can be reconstructed perfectly by just adding together the IMFs. This is actually the property that allows for an adaptive denoising of a noisy signal. In other words, the noisy components being captured by the higher order IMFs, are left out during the reconstruction, and only the IMFs that contain the signal energy are added to form the denoised signal. (For the interested reader a thorough analysis of the Hilbert-Huang transform is provided in Huang, 1998, and also in Huang et al., 2005.)

\section{Data analysis}

The L'Aquila earthquake occurred on Monday, 6 April 2009 at 01:32:39 UTC. The exact coordinates of the event were $42.334^{\circ} \mathrm{N}-013.334^{\circ} \mathrm{E}$, which correspond to a point $85 \mathrm{~km}$ northeast of Rome. This earthquake was the main shock of a series of pre-seismic events, which started in February and continued through March 2009. The earthquake preparation area is calculated as $511 \mathrm{~km}$ according to the Dobrovolsky equation (Dobrovolsky et al., 1979; Pulinets et al., 2004)

$r=10^{0.43 M} \mathrm{~km}$

where $M$ is the magnitude of the earthquake and $r$ is the size of the area in $\mathrm{km}$.

In an effort to increase the validity of the results of this study, we used data from three ionospheric stations, all of which were selected to ensure that their data was affected in a similar fashion by the solar activity-related phenomena. At the same time, the selection of the stations was such that the two, namely the Rome and San Vito stations, were located inside the earthquake preparation area, whereas the third, the Athens station, was located outside of it. Unfortunately the Gibilmana ionospheric station, which also fulfils the above spatial requirements, was inoperable during the time frame of interest, and therefore was unable to contribute to this study. According to the correlation coefficient theory we expect the Rome and San Vito measurements to show the disturbances caused by the earthquake, whereas the Athens measurements should be unaffected. Following this line of reasoning, the cross correlation coefficient of the Rome and San Vito signals is expected to be high, in contrast to the correlation coefficient of either station's readings with the Athens measurements.

The foF2 signals used were one-hour sample measurements from 10 March to 13 April 2009. This corresponds to a timeframe of 35 days, of which 27 days were prior to the event and 7 days were after the event. The data were downloaded from both the Space Physics Interactive Data Resource (SPIDR) and the Digital Ionogram (DIB) databases. Geophysical noise was removed from the signals using EMD, and then their denoised versions were used for the calculation of the respective correlation coefficients.

\section{Results and discussion}

The three stations used are shown in the map in Fig. 1, together with the earthquake preparation area, which is plotted in red. As we see the San Vito station is located inside the circle but its distance from the edge of the area is about $100 \mathrm{~km}$. In Fig. 2 the plot of the correlation coefficient between Rome-Athens, Rome-San Vito and San Vito-Athens, is presented. As shown, the cross correlation coefficient between Rome and Athens drops abruptly and takes the value of 0.27 on 16 March 2009, 22 days prior to the event. After that it stays greater than 0.8 , until 2 days prior to the event, and then it drops again to 0.72 . Moreover the coefficient falls even further to 0.7 on the day of the event, and after that it climbs back to values greater than 0.8 . The correlation coefficient between Rome and San Vito follows a very similar pattern, meaning that during the entire timeframe of interest it takes values greater than 0.9 , and only drops to 0.58 on 16 March, and again one day prior to the event. Similar to the Rome-Athens correlation coefficient, it also decreases on 


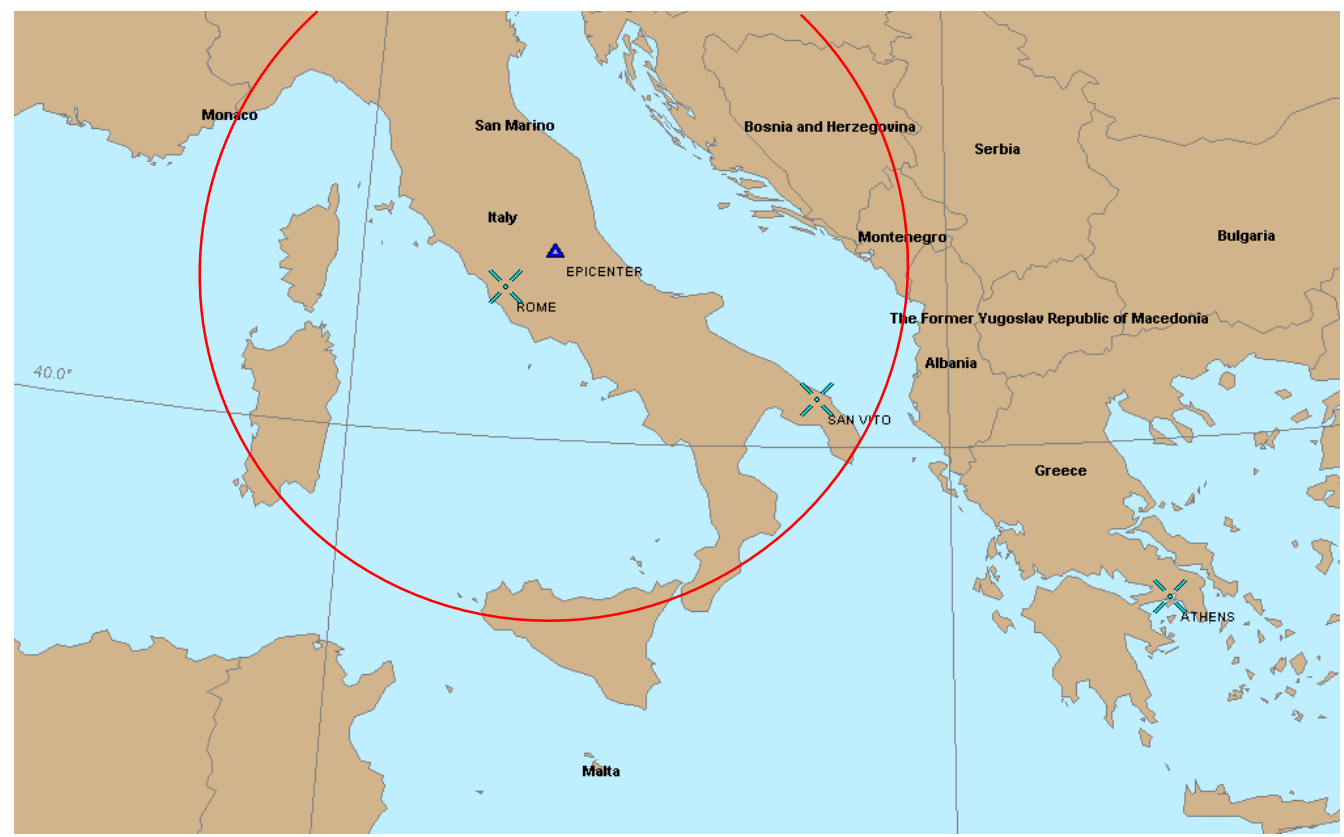

Fig. 1. The geographical location of Rome, San Vito and Athens the ionospheric stations, regarding the epicenter (blue triangle). Earthquake preparation area is plotted in red.

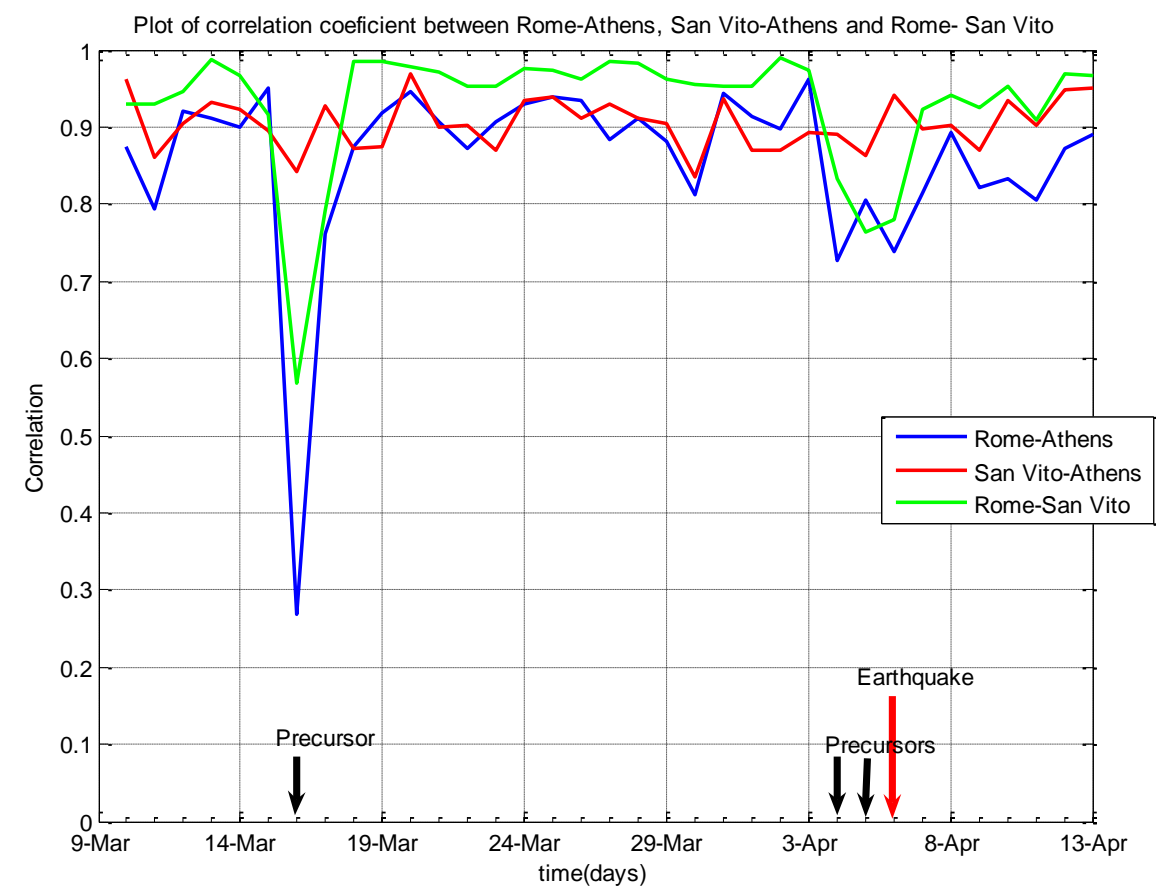

Fig. 2. Plot of the correlation coefficient of the denoised foF2 signals between Rome-Athens, Rome-San Vito, and San Vito Athens. Red arrow indicates the day of the seismic event and, black arrows represent ionospheric precursors.

the day of the event. Finally, the cross correlation coefficient between San Vito and Athens remains high throughout, staying greater than 0.84 .
Analyzing the above results we can make the following observations. First, we see that the ionosphere over Rome was disturbed by a strictly local event, due to the fact that its correlation coefficient with any of the other two stations follows a very similar pattern, with distinguishable drops on 
the exact same days. This statement is also verified by noticing the cross correlation coefficient between San Vito and Athens, which is relatively high during the entire timeframe of interest, and remains greater than 0.84 . Therefore, we conclude that the ionosphere over those two stations was unaffected by local phenomena during this period. Here we see that the experimental results verify an almost intuitive observation, meaning that we expected Rome to be affected by the earthquake, since it is located only $85 \mathrm{~km}$ from the event's epicenter.

Next, and coming as a relative surprise, is the fact that the San Vito station, although located inside the earthquake preparation area, behaves like it is outside of it. Specifically the fact that Rome-San Vito correlation coefficient does not stay high, means that the ionosphere over Rome was different than the ionosphere over San Vito during the examined time frame. The first possible explanation for this is that the area occupied by the anomalous electric field that produces the electron content variations of the ionosphere is not exactly a circle as the Dobrovolsky equation predicts. Therefore, any variation from the perfect circular shape will result in an area "squeezed" or "expanded" depending on the bearing from the epicenter. In a situation like this, it is logical to assume that a station very close to the circumference of the circle, which corresponds to the theoretical estimation of the earthquake preparation area, may either detect or not the earthquake. This phenomenon was also reported by Pulinets and attributed to the complex distribution of the anomalous electric field as it penetrates the ionosphere (Pulinets, 2004).

An interesting subject of research here would be the examination of how the ground morphology, impacts the propagation of the anomalous electric field generated prior to an earthquake, considering the fact that very high mountains exist in the area in between L'Aquila and San Vito. In other words, the mountainous terrain may be responsible for the lower intensity electric field over San Vito, compared to the theoretically expected, which subsequently was incapable to affect significantly the foF 2 measurements of the area. However, this assumption has to be validated by further analysis, supplemented by geomagnetic, geographical and geological data, and is beyond the scope of this paper.

Nevertheless, and in spite of the fact that the San Vito station did not feel the event, the foF 2 measurements over San Vito appear more similar to the Rome foF2 measurements than the Athens readings, judging by the fact that the correlation coefficient values between Rome-San Vito are always lower than the equivalent values between Rome and Athens. This observation leads to the conclusion that the ionosphere over San Vito was affected by the event, but the fluctuations in foF 2 were significantly smaller than those over Rome which was located very close to the epicenter. In any case the above result clearly shows that a selection of a station at the limits of the theoretical estimated earthquake preparation area is not the ideal choice when we apply the aforementioned theoretical model.
The last observation we make is that 16 March disturbance in the Rome ionosphere corresponds to a precursor 22 days prior to the event, something that is not typical for seismoionospheric preqursors. Indeed related studies report that ionospheric precursors appear during a timeframe from 112 days prior to $1-2$ days after the seismic event. The most reasonable explanation for this comes directly from the hypothesis of the geochemical processes that take place prior to and during an earthquake and are responsible for the nearground ionospheric plasma formation, and finally generate an anomalous electric field. Specifically, we assume that if those processes are in place and are so intense as to affect the ionospheric electron content, a relative strong seismic event is imminent. Therefore, a period of 12 days is about the maximum we expect for the precursors of a single event taking into account the experimental results gathered thus far. However, the L'Aquila case can be considered special due to the fact that a series of pre-seismic events from the same epicenter were reported from February 2009 up to the date of the main shock. Despite the fact that the magnitude of these events was below the acceptable limit to affect the ionosphere (Pulinets, 2004; Tsolis and Xenos, 2009), the cumulative result of each one's effect can justify the disturbance of the ionosphere, which finally explains the appearance of a precursor so far in advance of the main event. In other words, what we see on 16 March should not be considered a precursor of a single event on 6 April, but rather as an indication of an already disturbed ionosphere due to the series of smaller seismic events occurring at the same area. Yet, could this justify a so intense drop of the correlation between Rome and Athens, much more evident than the ones of the main event itself, and certainly disproportional to the magnitude of the earthquake? During our previous work we faced a similar situation where a precursor appeared 17 days prior to a strong 6.2 event. Since also in this case a number of smaller earthquakes occurred in the same area prior to the main event, we conclude that this correlation coefficient drop can be characterized as ionospheric precursor.

\section{Conclusions}

In this study we applied the Cross-Correlation Coefficient method combined with Empirical Mode Decomposition, in the analysis of the devastating L'Aquila earthquake in Italy. In order to achieve more qualitative results we used foF2 data from three different ionopsheric stations, namely Rome, San Vito and Athens. The foF2 signals were pre-processed using EMD to remove any geophysical noise, and then the cross correlation coefficient was calculated. The results of our study are summarized as follows.

1. The Rome station measurements were affected by the earthquake, producing precursors 22 days, 2 days, and 1 day prior to the event. 
2. The experimental results show that the ionosphere over a station located close to the border defined by the theoretical estimated earthquake preparation area, may not be affected adequately by the event, for the seismoionospheric precursors to appear.

3. When a series of intense seismic activities prior to the main shock is reported, precursors may appear more than 12 days prior to the event, which exceeds the maximum time frame reported so far regarding the appearance of seismo-ionospheric precursors.

Edited by: M. E. Contadakis

Reviewed by: A. Anastasiadis and another anonymous referee

\section{References}

Davies, K.: Ionospheric Radio, Peregrinus Ltd., London, UK, 1990.

Dobrovolsky, I. R., Zubkov, S. I., and Myachkin, V. I.: Estimation of the size of earthquake preparation zones, Pure Appl. Geophys., 117, 1025-1044, 1979.

Flandrin, P., Rilling, G., and Gonçalvès, P.: Empirical Mode Decomposition as a filter bank, IEEE Signal Proc. Lett., 11(2), 112114, 2004a.

Flandrin, P., Gonçalvès, P., and Rilling, G.: Detrending and denoising with Empirical Mode Decompositions, Eusipco, 12th European Signal Processing Conference, Vienna, Austria, 6-10 September 2004b.

Huang, N. E., Shen, Z., Long, S. R., Wu, M. L., Shih, H. H., Zheng, Q., Yen, N. C., Tung, C. C., and Liu, H. H.: The empirical mode decomposition and Hilbert spectrum for nonlinear and nonstationary time series analysis, P. Roy. Soc. Lond. A Mat., 454, 903-995, 1998.

Huang, N. E. and Attoh-Okine, N. O.: The Hilbert-Huang transform in engineering, Taylor \& Francis, 2005.
Kouris, S. S., Spalla, P., and Zolesi, B.: Could ionospheric variations be precursors of a seismic event? A short discussion, Ann. Geofis, 44(2), 395-402, 2001.

Liperovsky, V. A., Pokhotelov, O. A., Liperovskaya, E. V., Parrot, M., Meister, C. V., and Alimov, O. A.: Modification of sporadic E-layers caused by seismic activity, Surv. Geophys., 21, 449486, 2000.

Molchanov, O., Fedorov, E., Schekotov, A., Gordeev, E., Chebrov, V., Surkov, V., Rozhnoi, A., Andreevsky, S., Iudin, D., Yunga, S., Lutikov, A., Hayakawa, M., and Biagi, P. F.: Lithosphereatmosphere-ionosphere coupling as governing mechanism for preseismic short-term events in atmosphere and ionosphere, Nat. Hazards Earth Syst. Sci., 4, 757-767, 2004, http://www.nat-hazards-earth-syst-sci.net/4/757/2004/.

Namgaladze, A. A., Zolotov, O. V., Zakharenkova, I. E., Shagimuratov, I. I., and Martynenko, O. V.: Ionospheric total electron content variations observed before earthquakes: Possible physical mechanism and modeling, Geomagn. Aeronomy+, 49(2), 252-262, 2009.

Ouzounov, D. and Freund, F.: Ground-Atmosphere-Ionosphere interactions related to earthquakes: How can Earthscope help?, Earthscope Workshop: Making and Breaking a Continent, Report Snowbird, UT, USA, 2001.

Pulinets, S. A.: Alekseev, V. A., Legenka, A. D., and Hegai, V. V.: Radon and Metallic Aerosols Emanation before Strong Earthquakes and their Role in Atmosphere and Ionosphere Modification, Adv. Space Res., 20(11), 2173-2176, 1997.

Pulinets, S. A.: Ionospheric Precursors of Earthquakes; Recent Advances in Theory and Practical Applications, Terr. Atmos. Ocean. Sci., 15, 413-435, 2004.

Pulinets, S. A., Gaivoronska, T. B., Leyva Contreras, A., and Ciraolo, L.: Correlation analysis technique revealing ionospheric precursors of earthquakes, Nat. Hazards Earth Syst. Sci., 4, 697702, 2004, http://www.nat-hazards-earth-syst-sci.net/4/697/2004/.

Tsolis, G. S. and Xenos, T. D.: Seismo-ionospheric coupling correlation analysis of earthquakes in Greece, using empirical mode decomposition, Nonlin. Processes Geophys., 16, 123-130, 2009, http://www.nonlin-processes-geophys.net/16/123/2009/. 